\title{
Personalysis: Personality and Stress Analysis of Students
}

\author{
Atulya Gupta, Deepti Jain, Anika Sharma, Dishani, Meghal Singhal
}

\begin{abstract}
Stress is a mental condition that decreases the quality of life and influences almost every feature of life. Stress is a significant issue these days, particularly among students. The age that was once assumed to be the most cheerful phase of life is currently under a lot of pressure. Increment in levels of stress these days' prompts to numerous issues like misery, suicide, coronary episode, and stroke. In this paper, we are ascertaining the stress levels of students during their B. Tech degree. Our goal is to examine stress in the students at various focuses in his life. The impact that semester exam or placement tests has on student often goes unnoticed. The fact of understudy being in a relationship is not taken into account as a prime factor in calculating stress levels. In this research paper, we have considered that factor also. For calculating stress levels, students were asked some basic questions about how they feel, and what comes into mind when they see a picture and some personal questions based on their relationship status.

Keywords: Perceived Stress Scale, Mental stress, Stress awareness, Stress Factors, University Students
\end{abstract}

\section{INTRODUCTION}

Any change in environment that makes your body to react or cope up with that situation can be termed as stress. These reactions can be either physical, mental or emotional. It is normal to have stress in life. Events happening around you or things you do by yourself can put stress on your body. These stresses can be further classified into positive stress (eustress) and negative stress (distress). Eustress can include promotion of job or being given responsibilities. This type of stress keeps us alert and active. While stress becomes distress when a person continuously faces challenges without any relief or relaxation. As a result, the stress-related tensions start to build on the person. Stress is an unpreventable part of life and touches a wide variety of groups irrespective of their age, gender or economical status. Despite this fact, college students are at high risk of being under stressful situations. In accordance with [4], University students go through various social, environmental and psychological adjustment difficulties in the process of making themselves adapt to the new atmosphere. It happens because the education system of university has a big difference in its method of teaching,

Revised Manuscript Received on May 15, 2020.

* Correspondence Author

Atulya Gupta*, Department of Computer Science and Engineering, Bhagwan Parshuram Institute of Technology, Delhi, India

Deepti Jain, Department of Computer Science and Engineering, Faculty, Bhagwan Parshuram Institute of Technology, Delhi, India

Anika Sharma, Department of Computer Science and Engineering, Faculty, Bhagwan Parshuram Institute of Technology, Delhi, India

Dishani, Department of Computer Science and Engineering, Faculty, Bhagwan Parshuram Institute of Technology, Delhi, India

Meghal Singhal, Department of Computer Science and Engineering, Faculty, Bhagwan Parshuram Institute of Technology, Delhi, India

(C) The Authors. Published by Blue Eyes Intelligence Engineering and Sciences Publication (BEIESP). This is an open access article under the CC BY-NC-ND license (http://creativecommons.org/licenses/by-nc-nd/4.0/) academic requirements and relations between students. Stress seems to be common among college students' lives mainly because they need to ensure their academic survival as well as prepare themselves for their future career.Various studies have been conducted on college students to detect stress among them. Most of them have concluded that academic pressure every semester, improper time to study, high expectations from families, and fear of failure produces stress among them. This stress if exceeded can cause other health problems such as obesity, diabetes, heart attack etc. As per the studies, a student commits suicide every hour in different parts of the country.

According to Lancet report [1], our country has reported large number of suicide cases among the youngsters having age between fifteen and twenty-nine. Our inspiration for this application comes from the expansion of suicide rates and depression among youngsters in our own country. Every year around 8 lakh people commit suicide, out of which $17 \%$ are Indian. The numbers are huge. One of the way of diminishing these suicide rates is the detection as well as treatment of the mental stress among university students.

The main objective of this application is to identify the personality type and determine the stress level of the user efficiently through a fully automated system. This system will not only save a lot of time but will also provide fast and efficient results. It has a very simple user interface consisting of a few multiple choice questions.

User has to select one option according to his/her typical reactions and attitudes in various situations. These personality tests are also useful for companies to determine their employer's stress management, leadership qualities under various situations. Moreover, it is very important for any individual to know his/her personality type so that he/she can pick a suitable career for himself/herself.

\section{RELATED WORK}

Research paper [5] addresses the challenge of stress determination by developing and deploying machine learning enabled data driven by using Electroencephalogram biosensor. Here an integrated iOS mobile application is used that takes actions based on information obtained from Mindwave Mobile Set. Paper [7] provides an effective approach for the detection of stress levels using data provided from a physical activity tracker device developed by FITBIT. In paper [2] stress is recognized by developing expert systems based on artificial neural networks. Developed artificial neural network is trained using Physionet database's data. Research paper [3] investigates different neurofeedback stimulus contents like audio, video and games for mitigation of stress. Quantitative electroencephalogram (QEEG) features are compared for effectively measuring the contents. In addition, the topographic maps of activities were made for a better visual description.

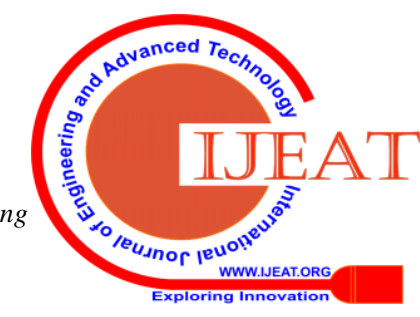


The results indicated that games exhibited higher effectiveness than audio and video contents for mitigating stress.

Paper [6] proposes two deep learning architectures that utilizes artificial neural networks technique. It concluded that the deep learning framework can be used as an automated system for identifying depression. In paper [8], a machine learning framework was introduced that involved electroencephalogram (EEG) signal for the analysis of stressed participants. Most of these papers include EEG signal based framework which is quite complicated and does not produce results with $100 \%$ accuracy as each algorithm is involved with some faults. In this paper, we are efficiently evaluating the stress level of a person by providing him/her a multiple choice-basedquestionnaire. It is an online web based application to identify the personality type and determine whether they have stress or not. Users have to give the answers according to their reactions and attitudes in different situations. The test will try to mitigate your stress management skills and what are your feelings about the kind of people you work with.

\section{DATASET AND PREPROCESSING}

The data was collected from 300 students from Bhagwan Parshuram Institute of Technology, Delhi. Relationship, family issues, recruitment and academic stress were the four major factors that were taken into account. A questionnaire was distributed to 300 students in different years of the university through online links. It had 20 questions based on the above 4 factors and each question had 5 options each (a) Strongly agree (b) Agree (c) Neutral (d) Disagree (e) Strongly disagree. A weight was assigned to each option and every question had a preference. After getting the responses, the students were divided into 3 categories - normal, stressed and highly stressed.

College students were asked basic questions about their feelings or reactions to various situations that they might have encountered in the recent past. Numerical weights were assigned to each answer which helped to calculate the total score to analyze stress level of the students.

\subsection{Perceived Stress Scale}

Developed by psychology professor Sheldon Cohen, Perceived Stress Scale is the most widely used instrument for stress perception It was developed to determine what kind of situations brings stress to a student and how he/she copes up with it.

Basically, it is a measure of degree to which one finds situations stressful in his/her life and helps them analyze how their lives have become unpredictable and uncontrollable. Some questions are made about normal life scenarios to analyze the person's stress levels. [8]PSS is useful in diagnosing the stress levels at an initial stage without investment of much money so that the threat of extreme stress can be reduced.

\section{SYSTEM ARCHITECTURE}

To overcome above problems Personalysis a single application for the user has been designed in such a way that itwill:
○ To make people aware about their stress levels, as there are many people who are not aware about thenegative impacts of high stress levels.

- To determine all the factors that cause in stress in today's generation.

- To prove that relationship status of individual makes a great impact on the individual's stress levels.

○ To help those people with high stress levels by giving them contact information about the psychologists.

\subsection{Flowchart}

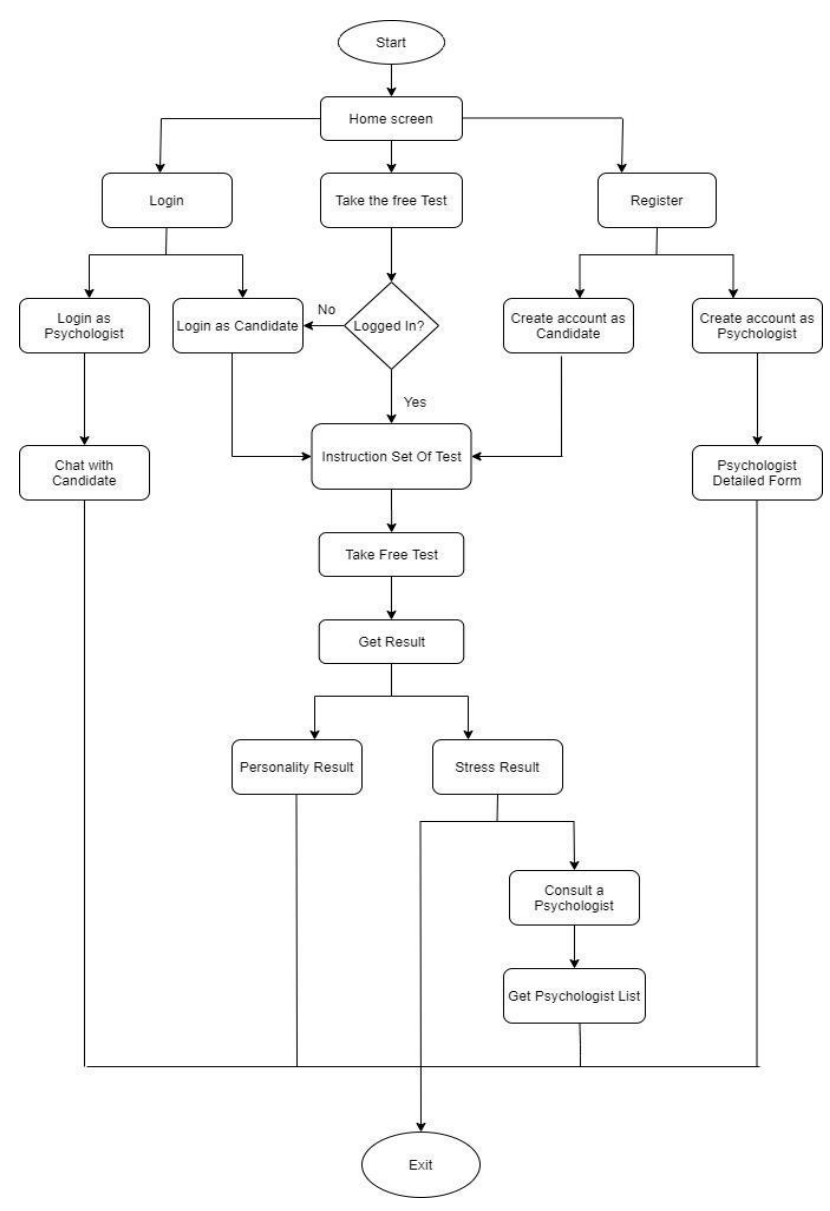

Figure 1.Flowchart of Project

\section{RESEARCH METHODOLOGY}

A structured questionnaire was made to collect the data from the students of three different years. It contained four major factors academic stress, relationship stress, family issues and personal problems and each factor had five questions each. So there were a total of 20 questions allotted to each student. Data analysis has been performed on the data using various statistical methods to check out the consistency of the input(questions) and their respective output (whether the person is stressed or not). To check the internal consistency or to find out how closely the questions are related, Cronbach's alpha has been applied. Technically, it is a coefficient of reliability or consistency. The value of alpha above 0.7 is considered to be satisfactory. [9]

Published By:

Blue Eyes Intelligence Engineering 
Formula for Cronbach's alpha is:

$\alpha=\frac{N \cdot \bar{c}}{\bar{v}+(N-1) \cdot \bar{c}}(1)$

Where,

$\mathrm{N}=$ number of items

$\mathrm{c}=$ average covariance between item pairs

$\mathrm{v}=$ average variance

To check the relation between the four factors and overall stress, correlation analysis has been made. [10] Firstly, Pearson correlation coefficient is found out which gives the magnitude of the association or correlation between two variables. It can take the values ranging from -1 to +1 . A higher positive value of the Pearson coefficient indicates the stronger association or significant relationship between the two variables. As the value of coefficient approaches to 0 , the relationship between the variables will go weaker.

Then $t$ values and $p$ values are calculated. The $t$ value is a result of statistical test while $p$ value means significance level.T test is a statistical test that helps us to determine if there is a significant difference between averages of two groups. It indicates that the data readings which are collected are not random and are probable not due to chance. Smaller t-values indicate more similarity between the two datasets while larger $t$ values lead to more differences between the groups. $\mathrm{P}$ value must be less than significance level(0.05) so that null hypothesis can be rejected.[10]

\section{DATA ANALYSIS AND INTERPRETATION}

Cronbach's alpha has been applied to dataset of different years.

Table 1.Cronbach's alpha

\begin{tabular}{ll}
\hline Year & Cronbach's alpha \\
\hline $2^{\text {nd }}$ year & 0.846504 \\
$3^{\text {rd }}$ year & 0.8702942 \\
$4^{\text {th }}$ year & 0.8177749
\end{tabular}

As all the values of cronbach's alpha are more than 0.8 , it means that there is good internal consistency between the questions and it is worth to go on with further analysis of data. Correlation analysis has been applied between each major factor of each year and the overall stress score. Pearson coefficient is calculated which indicated how each factor is related to overall stress.

Table 2.Pearson Coefficient

\begin{tabular}{ll|l|l}
\hline \multicolumn{1}{c|}{$\begin{array}{c}\text { Pearson Coefficient } \\
\text { with respect to overall } \\
\text { stress }\end{array}$} & $\mathbf{2}^{\text {nd }}$ year & $\mathbf{3}^{\text {rd }}$ year & $\mathbf{4}^{\text {th }}$ year \\
\hline Relationship & 0.865936 & 0.85602 & 0.845454 \\
Academic & 0.733621 & 0.7695 & 0.778389 \\
Recruitment & 0.83476 & 0.821162 & 0.781398 \\
$\begin{array}{l}\text { Personal (Family and } \\
\text { Peer pressure) }\end{array}$ & 0.858306 & 0.857513 & 0.804976 \\
\hline
\end{tabular}

Table 3.T value

\begin{tabular}{ll|l|l}
\hline $\begin{array}{l}\text { T value with respect } \\
\text { to overall stress }\end{array}$ & $\mathbf{2}^{\text {nd }}$ year & $\mathbf{3}^{\text {rd }}$ year & $\mathbf{4}^{\text {th }}$ year \\
\hline Relationship & 0.0116737 & 0.138194 & 0.0224142 \\
Academic & 0.000211 & 0.0000034 & 0.0000002 \\
$\begin{array}{l}\text { Recruitment } \\
\begin{array}{l}\text { Personal (Family and } \\
\text { Peer pressure) }\end{array}\end{array}$ & 0.199457 & 0.025639 & 0.165672 \\
\hline
\end{tabular}

Each factor has a quite low $\mathrm{t}$ value. It defines the similarities between the factors and overall stress development. It is indicated that each factor has an important role to play in evolution of stress in undergraduates.

$P$ value of each factor is computed as follows:

Table4. $P$ value

\begin{tabular}{cc|c|c}
\hline $\begin{array}{c}\text { T value with respect } \\
\text { to overall stress }\end{array}$ & $\mathbf{2}^{\text {nd }}$ year & $\mathbf{3}^{\text {rd }}$ year & $\mathbf{4}^{\text {th }}$ year \\
\hline Relationship & $<0.001$ & $<0.001$ & $<0.001$ \\
Academic & $<0.001$ & $<0.001$ & $<0.001$ \\
Recruitment & $<0.001$ & $<0.001$ & $<0.001$ \\
$\begin{array}{c}\text { Personal (Family and } \\
\text { Peer pressure) }\end{array}$ & $<0.001$ & $<0.001$ & $<0.001$ \\
\hline
\end{tabular}

This format of $\mathrm{p}$ value states that the values are so low that they cannot be expressed in decimals. So basically, it can be concluded that all the $\mathrm{p}$ values are much lower than 0.001 which shows very high significant levels among the factors.

\section{CONCLUSIONS}

Our survey or study included relationship as a major factor. It is one factor that is not considered as much and light has never been thrown upon it. Particularly, this factor has come into the picture with very high correlation with the overall stress in the undergraduates. It has its own different versions of stress and depression among young people. Firstly, it includes stress among the partners as there are relationship issues such as trust, possessiveness, mutual understanding, etc. Secondly, there are issues among parents and children as many children complain that their parents do not understand their emotions and feelings towards their partners and do not allow their children to be in a relationship at a young age.

A major portion of the study implied that the relationship issues were one of the top reasons for stress among students and it is a mutual thing between parentchild understanding and inter-partner understanding as well.

Published By:

Blue Eyes Intelligence Engineering

\& Sciences Publication

(C) Copyright: All rights reserved.

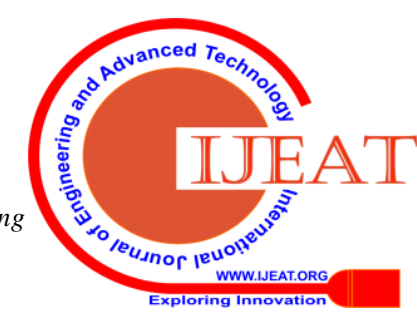




\section{Personalysis: Personality and Stress Analysis of Students}

It was also concluded that because of this major reason, students are not able to concentrate fully on their studies and academic life and have stress and depression in their life.

\section{RECOMMENDATIONS}

The college students are the future of this nation, they are the young minds that will become tomorrow's leaders;therefore, it is quite important to identify and manage the stress in college students. Stress usually models a great threat to the quality of life, not only for the individual but also for the people around it and society as a whole.

Some of the recommendations we can make, based on the research conducted, to reduce the stress in the college students are as follows:

- Workshops can play a major role in inspiring youngsters to adopt healthy and positive lifestyle.

- Acknowledge your feelings and keep a journal for your notes and thoughts.

- $\quad$ Spend time and share your emotions with your loved ones.

- Training programs and sessions for students to teach them how to deal with stress and anxiety during and before the examinations.

\section{REFERENCES}

1. Ahuja, R. (January 2019). Mental Stress Detection in University Students using Machine Learning Algorithms.

2. Alic, B. (June 2016). Classification of Stress Recognition using Artificial Neural Network.

3. Hafeez, Y. (September 2019). Investigating Neurofeedback Protocols for Stress Mitigation.

4. Ilmini, K. (January 2016). Persons' Personality Traits Recognition using Machine Learning Algorithms and Image Processing Techniques.

5. Khursheed, S. (July 2018). A System to Detect Mental Stress using Machine Learning and Mobile Development.

6. Mumtaz, W. (September 2019). A deep learning framework for automatic diagnosis of unipolar depression.

7. Padmaja, B. (February 2018). A Machine Learning Approach for Stress Detection using a wireless physical activity tracker.

8. Subhani, A. R. (July 2017). Machine Learning Framework for the Detection of MentalStress at DifferentLevels.

9. Mehtab, F. (Mar 2019). Personality Traits and Risk Perception of Indian Investors

10. chai, M. s. (Mar 2015). Personality, Coping and Stress Among University Students.

11. Dhiman, R. a. (2017). Influence of Personality Traits and Behavioral Biases on Investment Decision of Investors.

12. Reshma Radheshamjee Baheti, S. K. (October 2019). Detection and Analysis of Stress using Machine Learning.

13. S.K. Yadav, A. H. (June 2018). An Investigation of Occupational stress Classification by using Machine Learning

14. Trivedi, D. D. (June 2018). A Study of Causes of Stress and Stress Management Among Youth.

\section{AUTHOR'S PROFILE}

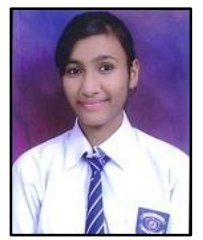

Atulya Gupta is a final year student in Bhagwan Parshuram Institute of Technology, Rohini, Delhi working under supervision of Ms. Deepti Jain. She belongs to Computer Science and Engineering Department.

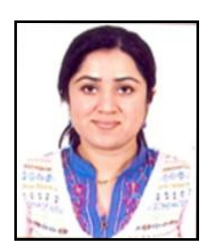

Deepti Jain is a lecturer at Computer Science and Engineering Department in Bhagwan Parshuram Institute of Technology, Rohini, Delhi. Her specializations are Big Data and Sentiment Analysis.

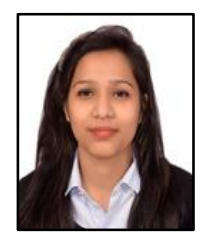

Anika Sharma is a final year student in Bhagwan Parshuram Institute of Technology, Rohini, Delhiworking under supervision of Ms. Deepti Jain. She belongs to Computer Science and Engineering Department.

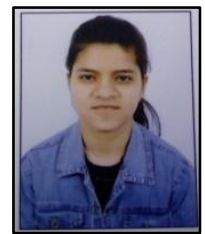

Dishani is a final year student in Bhagwan Parshuram Institute of Technology, Rohini, Delhi working under supervision of Ms. Deepti Jain. She belongs to Computer Science and Engineering Department.

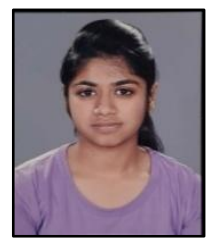

Meghal Singhal is a final year student in Bhagwan Parshuram Institute of Technology, Rohini, Delhi working under supervision of Ms. Deepti Jain. She belongs to Computer Science and Engineering Department.

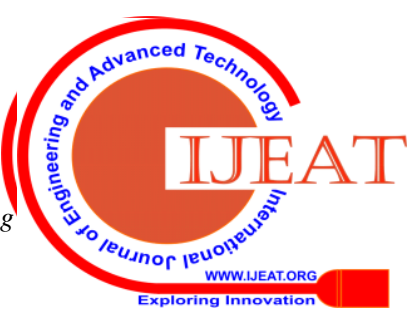

